\title{
THE EVALUATION OF BRUCELLA SPP. ISOLATION RATES IN RUMINANT ABORTION CASES BY USING DIFFERENT SELECTIVE MEDIA
}

\author{
Mustafa Sencer Karagul', Serkan Ikiz ${ }^{2}$ \\ ${ }^{1}$ Kartepe Vocational School of Equine Science, Kocaeli University, \\ 41080, Kocaeli, Turkey \\ ${ }^{2}$ Department of Microbiology, Faculty of Veterinary Medicine, \\ Istanbul University, 34320, Istanbul, Turkey
}

Received 6 March 2018; Received in revised form 12 May 2018; Accepted 4 July 2018

\begin{abstract}
The aim of this study is to evaluate the success of Brucella spp. isolation in ruminant abortion cases by using different selective media. To this end, 58 samples from ruminant abortion cases were utilized. 4 selective media; namely, Farrell Medium (FM), CITA Medium (CM), Modified Thayer Martin (MTM) and Jones \& Morgan (JM) were preferred for isolation. In addition to these, one medium with antibiotics was used to extend the range of the results. Suspensions prepared from organ and fetal stomach contents were inoculated to media plates and incubated at $37 \mathrm{C}^{\circ}$ for $5-8$ days in $5-10 \% \mathrm{CO}_{2}$ condition. Conventional biotyping method was used to identify Brucella isolates within the level of species and biovar. MTM (67.2\%) and Farrell $(65.5 \%)$ outperformed the other media with regards to isolation rate. However, regarding the inhibition ability against contaminant microrganisms, Farrell $(86.2 \%)$ and CITA $(72 \%)$ have the highest and second highest percentages respectively. The media's inhibition ability was examined in the samples in which Brucella spp. isolation occurred to be able to investigate the correlations between isolation and inhibition. Lower isolation percentage was observed in the samples in which the media displayed the lowest inhibition ability against contaminants. In this context, using two different selective media with high inhibition ability against contaminants may be recommended to enhance the isolation rate. Moreover, the components stimulating the growth of Brucella strains might be added to the media to obtain better results.
\end{abstract}

Key words: Biovar, Brucella spp., inhibition, isolation, selective medium

\section{INTRODUCTION}

Brucella spp. causes Brucellosis, which is one of the most common zoonotic diseases and which brings about important problems related to health and economy $(1,2,3)$. Brucellosis causes economic loss in husbandry; in addition, it poses a risk to public health as it is transmitted to people and causes infections through dairy products. It is possible to trace the roots of this disease in the $5^{\text {th }}$ plague of Egypt around $1600 \mathrm{BC}(4,5)$. It is defined as a chronic contagious disease causing

Corresponding author: Assist. Prof. Mustafa Sencer Karagul, PhD E-mail address: msencerk@hotmail.com

Present address: Kartepe Vocational School of Equine Science,

Kocaeli University, 41080, Kocaeli, Turkey

Phone: +90 (262) 37333 27; Fax: +90 (262) 3734198

Copyright: (C) 2018 Karagul M.S. This is an open-access article

published under the terms of the Creative Commons Attribution License

which permits unrestricted use, distribution, and reproduction in any

medium, provided the original author and source are credited.

Competing Interests: The authors have declared that no competing interests exist.

Available Online First: 16 September 2018

Published on: 15 October 2018

https://doi.org/10.2478/macvetrev-2018-0024 necrotic inflamatory infections and complications such as abortion, infertility, arthritis, orchitis and mastitis in susceptible hosts (6). According to the World Health Organization (WHO hereafter), there are 500,000 reported Brucellosis cases annually worldwide $(7,8)$. Due to the transmission of Brucella species via aerosol way, it is classified as a potential bioteror agent as well $(1,2)$. Moreover, Brucella organisms are described as belonging to risk group 3 microorganisms in the manual of WHO laboratory biosecurity $(9,10,11)$.

For the diagnosis of Brucellosis, isolation of bacteria is regarded as the gold standard (10). Test-and-slaughter and vaccination are important activities being implemented as part of eradication programs against Brucellosis (12). Furthermore, the investigation of the epidemiological source of the disease is as important as these implementetions (13). Isolation and identification of the etiological agent is necessary for this investigation, which can determine the source and the spread of the 
infection. As the number of contaminant organisms growing fast is big in the diagnostic material, using a selective medium for the isolation of Brucella spp. is necessary. $(14,15)$.

There is a great variety of selective media types including different basal media, antibiotic mixture, and concentration (16). Marin et al. (17) and Vicente et al. (18) contend that every medium has got a specific effect on Brucella species, its biovar and contaminants owing to the differences in media. After the first selective medium was created, new species and strains were found out in a variety of hosts and they were included in the Brucella genus; and this led to the extension of the ecological range of the Brucella genus. (1, 3, 19). For this reason, selective media, which have a significant role in isolation, are undeniably important for bacteriological isolation as a gold standard.

In this context, this study investigates the success of Brucella spp. isolation by using different selective media.

\section{MATERIAL AND METHOD}

This study was carried out in the Pendik Veterinary Control Institute between 2014 and 2015. 51 organs and 7 fetal stomach content of abortion cases were utilized. The media included in this study involves 4 different selective media and the Tryptic Soy Agar (TSA) as a non-selective medium. The content of Farrell (20), CITA (21),
Modified Thayer Martin (14), and Jones and Morgan (22) as selective media is illustrated in Table 1. In addition to these, one medium with antibiotics was used to extend the range of results. This medium is called 'Brucella medium' and labelled as BM in the following sections of this study.

Amphotericin-B has been preferred instead of natamycin or cycloheximid, which is part of the antimicrobial content of the JM medium. It is considered to be one of the antifungal agents suggested for the selective media for the first isolation of Mycobacterium spp. (23), Campylobacter spp. (24) and Brucella spp. (21).

For this study, the basal medium required for the selective media was prepared and sterilized by autoclaving $\left(121^{\circ} \mathrm{C} \pm 3^{\circ} \mathrm{C}, 15\right.$ minutes $)$. Antibiotics and sterile new born calf sera were added to the media at about $56^{\circ} \mathrm{C}$ depending on their contents (25). Sterility controls of media were conducted after they were incubated at $37^{\circ} \mathrm{C}$ for 48 hours (26). The organ suspensions were prepared from organ samples diluted $1 / 10$ in a phosphate buffered saline in a biosafety cabinet $(18,27)$.

Organ suspensions and fetal stomach content were inoculated to media and incubated in $37^{\circ} \mathrm{C}$, 5-10\% $\mathrm{CO}_{2}$ condition for 5-8 days. Biovar identification of isolates was implemented according to $\mathrm{CO}_{2}$ requirement, $\mathrm{H}_{2} \mathrm{~S}$ production, growth in media containing thionin $(20 \mu \mathrm{g} /$ $\mathrm{ml})$, basic fuchsin $(20 \mu \mathrm{g} / \mathrm{ml})$, safranine $(100 \mu \mathrm{g} /$ $\mathrm{ml}$ ), penicillin, streptomycin, and i-erythritol sensitivity, lysis with Tibilisi (TbØ $10^{4}$ RTD) and

Table 1. The contents of the selective media

\begin{tabular}{lccccc}
\hline Content & Farrell & CITA & MTM & JM & BM \\
\hline Basal medium & BMB-CS & BAB-CS & GC-H & SDA-CS & TSA-CS \\
Bacitracin (IU/L) & 25,000 & - & - & 25,000 & - \\
Polymyxin (IU/L) & 5,000 & - & - & 6,000 & 6,000 \\
Nalidixic acid(mg/L) & 5 & - & - & - & - \\
Amphotericin-B (mg/L) & - & 4 & 2.5 & 4 & 4 \\
Natamycin (mg/L) & 50 & - & - & - & - \\
Nitrofurantain(mg/L) & - & 10 & 10 & - & 10 \\
Vancomycin(mg/L) & 20 & 20 & 3 & - & 20 \\
Colistin (mg/L) & - & 7.5 & 7.5 & - & - \\
Nystatin (IU/L) & 100,000 & 100,000 & 100,000 & - & - \\
Erythritol (g/L) & - & - & - & - \\
\hline
\end{tabular}

BMB-CS: Brucella medium base with calf sera

BAB-CS: Blood agar base with calf sera

GC-H: GC agar base with hemoglobin

SDA-CS: Serum dextrose agar

TSA-CS: Trypton soy agar with calf sera 
$\mathrm{R} / \mathrm{C}$ phages and agglutination with monospecific $\mathrm{A}$ and $\mathrm{M}$ antisera. Media including streptomisin $(2,5 \mu \mathrm{g} / \mathrm{ml})$, penicillin $(5 \mathrm{IU} / \mathrm{ml})$ and i-erythritol $(1 \mathrm{mg} / \mathrm{ml})$ were used in the identification of vaccine strains. In addition, we have observed the growth level of contaminant microrganisms.

The classification categories for the inhibition ability of the media against contaminant microorganisms in this study were total inhibition (TI) and partial inhibition (PI). These categories were formed regarding the diffuseness of the contaminant growth through counting the colony forming units (cfu) (26). When the contaminant colony counts were taken into account, the media's inhibition ability was listed by focusing on the range of the contaminant burden. We have classified the ranges into 4 groups; namely, 1 total inhibition group without any contaminant colonies and 3 partial inibition groups with less than 10, ones between 10 and 100, and ones with more than 100 colonies $(26,28,29)$. Pearson Chi-Square Test in SPSS18.0 program was used to evaluate the results of this study.

\section{RESULTS}

Biyotyping results of the isolates and the media in which isolation was carried out are illustrated in Table 2. The table also shows the inhibition level of the contaminants for each medium in every single sample.

Table 2. The isolation and inhibition results of selective media for each sample

\begin{tabular}{|c|c|c|c|c|c|c|c|}
\hline No & Animal & $\mathbf{T I}^{*}$ & $\begin{array}{c}\mathrm{PI}^{\dagger} \\
(<\mathbf{1 0 f f u})\end{array}$ & $\begin{array}{c}\mathrm{PI}^{\ddagger} \\
(10-100 \mathrm{cfu})\end{array}$ & $\begin{array}{c}\mathrm{PI}^{\S} \\
(>100 \mathrm{cfu})\end{array}$ & $\begin{array}{l}\text { Brucella } \\
\text { isolation }\end{array}$ & Biovar \\
\hline 1 & Sheep & - & $\mathrm{JM}$ & CM, FM & BM, MTM & - & - \\
\hline 2 & Goat & - & - & FM & $\begin{array}{c}\text { BM, JM, CM, } \\
\text { MTM }\end{array}$ & FM & B.melitensis bv3 \\
\hline 3 & Sheep & FM & $\mathrm{CM}$ & $\begin{array}{l}\text { JM, BM } \\
\text { MTM, }\end{array}$ & - & - & - \\
\hline 4 & Sheep & FM & $\begin{array}{l}\text { CM, JM } \\
\text { MTM, }\end{array}$ & $\mathrm{BM}$ & - & - & - \\
\hline 5 & Sheep & ALL' & - & - & - & - & - \\
\hline 6 & Goat & $\mathrm{JM}$ & - & - & $\begin{array}{c}\text { CM, FM MTM, } \\
\text { BM }\end{array}$ & MTM, BM, JM & B.melitensis bv 1 \\
\hline 7 & Sheep & - & JM, MTM & - & BM, FM, CM & BM, JM MTM & B.melitensis bv3 \\
\hline 8 & Sheep & ALL & - & - & - & ALL & B.melitensis bv3 \\
\hline 9 & Sheep & FM, BM,CM & MTM, JM & - & - & ALL & B.melitensis bv1 \\
\hline 10 & Sheep & FM, BM CM & JM, MTM & - & - & ALL & B.melitensis bv 3 \\
\hline 11 & Sheep & $\begin{array}{c}\text { FM, JM MTM, } \\
\text { CM }\end{array}$ & $\mathrm{BM}$ & - & - & ALL & B.melitensis bv3 \\
\hline 12 & Sheep & $\mathrm{JM}$ & MTM & FM, CM, BM & - & ALL & B.melitensis bv3 \\
\hline 13 & Sheep & FM & - & - & $\begin{array}{l}\text { CM, JM, } \\
\text { BM,MTM }\end{array}$ & ALL & B.melitensis bv3 \\
\hline 14 & Sheep & $\begin{array}{c}\text { FM, BM MTM, } \\
\text { CM }\end{array}$ & $\mathrm{JM}$ & - & - & ALL & B.melitensis bv 3 \\
\hline 15 & Sheep & ALL & - & - & - & ALL & B.melitensis bv3 \\
\hline 16 & Sheep & FM & - & $\begin{array}{l}\text { MTM, CM, } \\
\text { BM }\end{array}$ & $\mathrm{JM}$ & $\begin{array}{l}\text { FM, BM, } \\
\text { CM,MTM }\end{array}$ & B.melitensis bv3 \\
\hline 17 & Sheep & ALL & - & - & - & ALL & B.melitensis bv 3 \\
\hline 18 & Sheep & - & FM & - & $\begin{array}{c}\text { MTM, CM, BM, } \\
\text { JM }\end{array}$ & ALL & B.melitensis bv 1 \\
\hline 19 & Sheep & - & - & - & ALL & ALL & B.melitensis bv3 \\
\hline 20 & Sheep & - & FM & - & $\begin{array}{c}\text { MTM, CM, JM, } \\
\text { BM }\end{array}$ & FM & B.melitensis bv3 \\
\hline 21 & Goat & - & - & - & ALL & MTM, BM, CM & B.melitensis bv3 \\
\hline
\end{tabular}




\begin{tabular}{|c|c|c|c|c|c|c|c|}
\hline 22 & Cattle & $\mathrm{JM}$ & FM & $\begin{array}{l}\text { CM, BM, } \\
\text { MTM }\end{array}$ & - & $\begin{array}{c}\text { JM, FM, MTM, } \\
\text { CM } \\
\text { BM(WG }\left(\mathrm{WG}^{\uparrow}\right)\end{array}$ & $\begin{array}{l}\text { B.abortus } \\
\text { S-19 }\end{array}$ \\
\hline 23 & Sheep & - & - & ALL & - & ALL & B.melitensis bv3 \\
\hline 24 & Goat & $\begin{array}{c}\text { FM,CM, BM, } \\
\text { MTM }\end{array}$ & $\mathrm{JM}$ & - & - & - & - \\
\hline 25 & Sheep & CM, FM, BM & JM, MTM & - & - & ALL & B.melitensis bv1 \\
\hline 26 & Sheep & - & - & FM & $\begin{array}{l}\text { MTM, CM, BM, } \\
\text { JM }\end{array}$ & FM & B.melitensis bv3 \\
\hline 27 & Sheep & - & - & FM, CM & MTM, JM,BM & ALL & B.melitensis bv3 \\
\hline 28 & Goat & - & - & FM & $\begin{array}{c}\text { MTM, CM, JM, } \\
\text { BM }\end{array}$ & - & - \\
\hline 29 & Sheep & $\begin{array}{l}\text { FM, CM, } \\
\text { BM,MTM, }\end{array}$ & $\mathrm{JM}$ & - & - & - & - \\
\hline 30 & Sheep & ALL & - & - & - & - & - \\
\hline 31 & Sheep & - & FM & - & $\begin{array}{c}\text { MTM, CM, JM, } \\
\text { BM }\end{array}$ & ALL & B.melitensis bv1 \\
\hline 32 & Sheep & - & $\mathrm{JM}$ & $\begin{array}{l}\text { BM, CM, } \\
\text { MTM,FM }\end{array}$ & - & ALL & B.melitensis bv 3 \\
\hline 33 & Sheep & - & FM & $\begin{array}{c}\text { CM,BM } \\
\text { MTM }\end{array}$ & $\mathrm{JM}$ & - & - \\
\hline 34 & Sheep & FM,CM, MTM & JM, BM & - & - & - & - \\
\hline 35 & Sheep & - & - & - & ALL & - & - \\
\hline 36 & Sheep & - & FM & - & $\begin{array}{l}\text { CM, BM, MTM, } \\
\text { JM }\end{array}$ & - & - \\
\hline 37 & Sheep & - & - & - & ALL & - & - \\
\hline 38 & Sheep & ALL & - & - & - & - & - \\
\hline 39 & Sheep & - & - & - & ALL & - & - \\
\hline 40 & Sheep & - & - & ALL & - & ALL & B.melitensis bv3 \\
\hline 41 & Sheep & - & - & JM, CM, FM & BM, MTM & JM, CM, FM, BM & B.melitensis Rev1 \\
\hline 42 & Sheep & ALL & - & - & - & ALL & B.melitensis bv3 \\
\hline 43 & Cattle & - & $\mathrm{JM}$ & CM,MTM & FM, BM & ALL & B.abortus bv3 \\
\hline 44 & Sheep & FM, CM & JM, BM & MTM & - & MTM & B.abortus bv3 \\
\hline 45 & Cattle & - & - & $\begin{array}{l}\text { MTM, CM } \\
\text { BM, FM, }\end{array}$ & JM & ALL & B.abortus bv3 \\
\hline 46 & Sheep & CM,JM, MTM, & $\mathrm{BM}$ & FM & - & ALL & B.melitensis bv1 \\
\hline 47 & Sheep & MTM & CM, JM & FM, BM & - & ALL & B.melitensis bv3 \\
\hline 48 & Sheep & ALL & - & - & - & ALL & B.melitensis bv3 \\
\hline 49 & Sheep & ALL & - & - & - & ALL & B.melitensis bv3 \\
\hline 50 & Cattle & - & $\begin{array}{l}\text { FM, JM } \\
\text { MTM, }\end{array}$ & CM, BM & - & ALL & B.abortus bv3 \\
\hline 51 & Cattle & $\mathrm{CM}$ & MTM, JM & FM, BM & - & ALL & B.abortus bv3 \\
\hline 52 & Cattle & ALL & & & & ALL & B.abortus bv3 \\
\hline 53 & Cattle & ALL & & & & ALL & B.abortus bv3 \\
\hline 54 & Cattle & ALL & & & & ALL & B.abortus bv3 \\
\hline 55 & Cattle & - & - & FM & $\begin{array}{c}\text { CM, MTM, JM, } \\
\text { BM }\end{array}$ & ALL & B.abortus bv3 \\
\hline 56 & Cattle & $\begin{array}{c}\text { FM, JM, CM, } \\
\text { BM }\end{array}$ & MTM & - & - & ALL & B.abortus bv3 \\
\hline 57 & Cattle & ALL & - & - & - & ALL & B.abortus bv 3 \\
\hline 58 & Cattle & ALL & - & - & - & MTM & B.abortus bv 3 \\
\hline
\end{tabular}

*.TI (Total Inhibition): The media listed in this column inhibited all the contaminants. No contaminant colony was observed

$\uparrow$. PI (Partial Inhibition)<10cfu: The media listed in this column partially inhibited the contaminants. Less than 10 contaminant colonies were observed

†. PI (Partial Inhibition)10-100cfu: The media listed in this column partially inhibited the contaminants. Between 10 and 100 contaminant colonies were observed

$\S$. PI (Partial Inhibition) $>100 \mathrm{cfu}$ : The media listed in this column partially inhibited the contaminants. More than 100 contaminant colonies were observed

$\|$. ALL It represents all the media

I. WG: (Weak Growth) It shows that growth diffuseness in this medium is less than the other media 
Table 3. The number of Brucella spp. isolations and the distribution of inhibition ability

\begin{tabular}{|c|c|c|c|c|c|c|}
\hline Media & TI & PI (<10 cfu) & PI (10-100cfu) & PI & $(>100$ cfu $)$ & Brucella spp. isolation \\
\hline Farrel & 28 & 7 & 15 & & 8 & 38 \\
\hline CITA & 26 & 3 & 13 & & 16 & 36 \\
\hline МTM & 21 & 9 & 10 & & 18 & 39 \\
\hline $\mathbf{J M}$ & 20 & 16 & 4 & & 18 & 36 \\
\hline BM & 21 & 4 & 13 & & 20 & $37+1(\mathrm{~S}-19)$ \\
\hline
\end{tabular}

Table 4. The isolation and the inhibition ability of the media in percentages

\begin{tabular}{lcc}
\hline Media & Isolation $\%$ & Inhibition\% \\
\hline Farrel & 65.5 & 86.2 \\
CITA & 62 & 72.4 \\
MTM & 67.2 & 68.9 \\
JM & 62 & 68.9 \\
BM & 65.5 & 65.5 \\
\hline
\end{tabular}

According to the aforementioned results, isolations could not be carried out in every medium. Moreover, selective media had different performance levels in terms of inhibition ability against contaminants. In addition to these, even though B. abortus S19 was isolated in Brucella medium after inoculation of sample No. 22, the growth of strain was at weak growth (WG) level and the growth diffuseness was clearly lower than the other media. The detailed results in Table 2 are summarized in Table 3 and Table 4 . The numbers of Brucella isolation and the distribution of inhibition abilities are listed in Table 3.

Table 3 shows that MTM medium's isolation percentage is the highest one with 39 Brucella spp. isolates when we consider all 58 samples. Moreover, Farrell medium's performance is a lot better than the other media regarding the inhibition ability.

We have listed the inhibition and isolation ability of the media as percentages in Table 4 so as to clarify the numbers in Table 3 . The percentages of the inhibition ability in Table 4 was found by taking the sum of TI and PI inhibition abilities without including the PI ( $>100 \mathrm{cfu}$ ). Even if two of them (PI $<10 \mathrm{cfu}, \mathrm{PI}=10-100 \mathrm{cfu}$ ) show partial inhibition ability, they are considered to be sufficient inhibition ability as they make the isolation of Brucella spp possible.

The media's isolation and inhibition ability illustrated in Table 4 was analyzed statistically. The media's isolation percentages are similar and they are not statistically significant. There are far more differences in the media's inhibition ability against contaminants than their isolation ability. The statistical analysis of these differences is outlined in Table 5.

In Table 4, all the media except the Farrell medium have similar inhibition ability percentages. Therefore, in Table 5 statistical analyses were carried out only between the results of Farrell, which has the highest inhibition percentage, and the other media. The $p$ value between Farrell and the

Table 5. The results of the statistical analysis related to the media's inhibition ability

\begin{tabular}{lcc}
\hline Chi-SquareTest & \multicolumn{2}{c}{ Inhibition ability } \\
Pearson Chi-Square & $\mathbf{X}^{2}$ value & P value \\
\hline Farrell \& BM & 6.778 & 0.009 \\
Farrell \& MTM & 4.957 & 0.026 \\
Farrell \& JM & 4.957 & 0.026 \\
Farrell \& CITA & 3.362 & 0.067 \\
\hline
\end{tabular}


Table 6. The distribution of the media's inhibition ability in the samples where Brucella spp. was isolated

\begin{tabular}{|c|c|c|c|c|c|}
\hline Medium & Brucella spp. isolation & TI & PI $<10$ cfu & PI 10-100cfu & PI $>100$ cfu \\
\hline Farrell & 38 & 19 & 5 & 13 & $1 \quad(1 / 8: 12.5 \%)$ \\
\hline CITA & 36 & 18 & $1(1 / 3: 33.3 \%)$ & 11 & $6(6 / 16: 37.5 \%)$ \\
\hline MTM & 39 & 15 & 8 & 8 & $8 \quad(8 / 18: 44.4 \%)$ \\
\hline $\mathbf{J M}$ & 36 & 16 & 10 & 3 & $7 \quad(7 / 18: 38.8 \%)$ \\
\hline BM & 38 & 15 & $2(2 / 4: 50 \%)$ & 10 & $11(11 / 20: 55 \%)$ \\
\hline
\end{tabular}

other media except CITA medium is smaller than 0.05; therefore, the difference between Farrell and CITA is statistically insignificant but the difference between Farrell and the other media is statistically significant.

In order to investigate the correlations between isolation and inhibition, the inhibition ability of the media was examined in the samples in which Brucella spp. isolation occurred. The distribution of the media's inhibition ability for these samples is listed in Table 6.

Based on the distribution results, it can be stated that the highest Brucella spp. isolation for each medium was obtained in the samples in which all the contaminants were totally inhibited (TI). In addition, in Table 3, the distribution of the media's inhibition ability was made based on 58 samples regardless of Brucella spp. isolation. In this table, on the other hand, the media's inhibition ability was calculated for the samples in which Brucella spp. was isolated. When the values of these two tables were evaluated, the isolation percentage of the samples in which the contaminants were partially inhibited at the level of PI $>100$ was lower than the other levels (TI, PI $<10$, and PI 10-100), except for two results shown in italics. These low percentages of isolation were given in the last column of Table 6 .

\section{DISCUSSION}

Regarding the number of isolations, MTM has the highest and Farrell medium has the second highest isolation percentage. Marin et. al. (17) obtained a higher isolation sensitivity for Brucella melitensis in MTM than they did in Farrell, which was actually developed for Brucella abortus isolation. In this study, it was found out that using these two media simultaneously could increase the isolation percentage up to $74.1 \%$ with 43 successful isolations (15). In OIE Cattle Brucellosis Chapter, too, using two media simultaneously to be able to augment the isolation sensitivity is recommended
(17, 11). Similarly, Ferreira et al. (30) suggested using more than one selective medium to enhance the isolation sensitivity.

When the inhibition ability is taken into consideration, the Farrell medium has the highest percentage while CITA has the second highest percentage. Even though the difference between the Farrell medium and the CITA medium is statistically insignificant, the difference between the Farrell medium and the other media is statistically significant. It is pointed out that the Farrell medium is able to inhibit most of the contaminants; thus, it is the most common selective medium for the bacteriological diagnosis of Brucellosis (21). In the study by Vicente et al. (18) where CITA and Farrell were compared and contrasted, both media were found to be similar in their inhibition abilities against the contaminants and they showed good results when they were used together. De Miguel et al. (21) stated in their study, in which they developed the CITA medium, that CITA could inhibit most of the contaminants and it had better isolation sensitivity than those of MTM and Farrell. In a similar study, Brucella agar, the Farrell and CITA media were compared and contrasted and despite the same number of isolations in each medium, Farrell had the highest inhibition ability against contaminants and it is regarded as the best selective medium for microbiological diagnosis (31).

According to the results, it can be stated that the highest Brucella spp. isolation for each medium was obtained in the samples in which all the contaminants were totally inhibited (TI). When all the 58 samples were evaluated, the number of the samples where all the contaminants were totally inhibited is bigger in Farrell and CITA than in the other media. In his study, Farrell classified the growth levels of contaminants as $1+, 2+$ and $3+(20)$. He stated that most of the Brucella spp. isolations were obtained in the samples with contaminant growth at $1+$ level. The findings of this study, too, indicate that the increase in the inhibition ability of the selective media plays an important role in 
enhancing isolation sensitivity. It was also pointed out that although the antibiotics added to the media could decrease contamination, B. abortus colonies might be masked by the excessive amount of contaminant growth due to the length of incubation period (29). For this reason, in such samples, the isolation rate can decline in the selective media which are not as effective as Farrell and CITA in terms of contaminant inhibition.

Brucella bacteria are fastidious microorganisms and require a longer period of incubation when we compare them with contaminants growing fast in the samples $(14,15,25)$. The generation period of Brucella organisms, which is 2.5-3.5 hours, is considered as a long duration, too (32). It was also pointed out that it may take some more days to observe colonies on the selective media as compared to the usual incubation period on non-selective media (25). In our study, as well, we found out that when we passage the Brucella suspect colonies one day later, we could not identify Brucella colonies due to the contaminants which hid the Brucella colonies. For this problem, Alton et al. (25) recommended that Brucella suspect colonies should be passaged before the contaminants spread on the media's surface and they should be checked three days after the incubation. Using solid medium is considered to be the most satisfactory method for isolation as it can facilitate the isolation of Brucella colonies and it can also minimize the risk of mixing Brucella colonies with the other fast growing microorganisms $(11,25)$.

In the samples in which the contaminants were partially inhibited at the level of PI $>100$, the isolation percentage was the lowest or close to the lowest. The reason behind the low isolation percentage might be predicted as the contaminants covering the medium's surface. In a study by Stack et al. (15), it was stated that they could not spot the Brucella bacteria colonies in some of the artificially infected milk samples. They contend that the reason behind it was that contaminants in the milk samples disguised the Brucella colonies. Based on the findings of this study, it is possible to say that an increase in the inhibition ability of the media may facilitate Brucella spp. isolation and it may lead to an increase in the isolation sensitivity. In this sense, following and improving the inhibition abilities of the media according to the samples with different contaminant microflora might increase the isolation rate.

Her et al. (27) developed a selective medium which includes indicator neutral red for the isolation of Brucella abortus strains. This medium can facilitate the observation of the Brucella spp. colonies more easily by differentiating them from contaminants. A novel approach might be passaging the slow-growing Brucella bacteria with the help of the indicators before they are masked by contaminants. This approach may be a useful tool to increase the low isolation rate in samples where contaminants are inhibited inadequately. In our study, as well, lower inhibition ability level led to a lower isolation percentage; therefore, it might be a good idea to focus on the development of such kind of media. That kind of development and modification in the Brucella selective media as well as the findings of this study indicate the significance of contaminant inhibition for a better isolation percentage.

The medium with antibiotics, which was labeled as BM in this study, includes erythritol which stimulates the growth of Brucella strains. $\mathrm{BM}$ is composed of fewer antimicrobial agents compared to the media with high inhibition ability. Although BM has the lowest inhibition ability, it does not have the lowest isolation rate. This fact might be interpreted as the positive effect of the erythritol component it includes. The isolation rate can decrease in the samples in which contaminant organism burden increases qualitatively and quantitatively, while the number of the target bacteria decreases. In the development of media, components such as erythritol provoking growth and antimicrobial agents providing inhibition can be added to the media.

In the Modified Brucella selective (MBS) medium developed by Her et al. (27) for B. abortus strains, too, erythritol was used to provoke and improve the delayed growth of strains among antibiotic mixtures. Erythritol is also mentioned as a sugar alcohol which is effective in the tissue tropism of Brucella bacteria in ruminants $(27,33$, 34). However, it is believed that erythritol does not stimulate $(35,36)$ but inhibits the growth of the S19 strain (34, 37). Conversely, S19 isolation took place in BM as weak growth in one of the samples (Table 2, no:22). Alton et al. (25) suggested that the mutation level of S19 strains against erythritol tolerance was high. They also stated that even though some suspected S19 isolates resembled S19 in other tests, they could grow in erythritol. It is pointed that the reason behind this weak growth in this sample might be what Alton et al. (25) suggested above. In light of the findings of this study, it might be stated that adding erythritol component to the selective media will provoke growth of Brucella strains except S19 and it might be recommended as a way of increasing isolation sensitivity. 


\section{CONCLUSION}

To sum up, using two different media with high inhibition ability like Farrell simultaneously might be helpful while choosing the appropriate selective media. In the process of developing media, on the other hand, adding components that will provoke Brucella spp. growth should be considered. Moreover, checking the performance of media repeatedly will be beneficial for obtaining better isolation rates. In these repeated controls, qualitatively and quantitatively different microbiol burden of the field samples should also be taken into consideration.

\section{CONFLICT OF INTEREST STATEMENT}

The authors declared that they have no potential conflict of interest with respect to the authorship and/or publication of this article.

\section{ACKNOWLEDGMENT}

This article was originated from part of a $\mathrm{PhD}$ thesis by Mustafa Sencer Karagul. The research was approved by the Local Ethics Committee for Animal Experiments, Istanbul University, Istanbul, Turkey (Ethics Committee Decision No: 2014-84).

\section{REFERENCES}

1. Godfroid J., Cloeckaert A., Liautard J.P., Kohler S., Fretin D., Walravens K., Garin-Bastuji B., Letesson J.J. (2005). From the discovery of the Malta fever's agent to the discovery of a marine mammal reservoir, brusellosis has continously been a re-emerging zonosis. Vet. Res. 36, 313-326. https://doi.org/10.1051/vetres:2005003 PMid:15845228

2. Songer, J.G., K.W. Post. (2012). Brusella cinsi. [Brusella genus]. In: O. Ang, Y. Ozgur, (Eds.), Veteriner Hekimlik Mikrobiyolojisi-Hayvan Hastalığı Etkeni Olan Bakteriler ve Mantarlar. [Veterinary Microbiology: Bacterial and Fungal Agents of Animal Disease] (pp. 200-207). Istanbul, Turkey: Nobel Press. [in Turkish]

3. Yumuk Z., O'Callaghan D. (2012). Brucellosis in Turkey-an overview. Int. J. Infect. Dis. 16 (4): 228-35. https://doi.org/10.1016/j.ijid.2011.12.011 PMid:22333223

4. Pappas G., Panagopoulou P., Chistou L., Akritidis N. (2006). Brucella as a biological weapon. Cell. Mol. Life. Sci. 63, 2229-2236. https://doi.org/10.1007/s00018-006-6311-4 PMid:16964579

5. Seleem M.N., Boyle S.M., Sriranganathan N. (2010). Brucellosis: A re-emerging zoonosis. Vet. Microbiol. 140 (3-4): 392-398.

https://doi.org/10.1016/j.vetmic.2009.06.021 PMid:19604656

6. Aydın N. (1997). Gram negatif küçük çomaklar -Brusella infeksiyonlar1. [Small gram negative cocci - Brucella infections]. In: M. Arda, A. Minbay, N. Leleoglu, N. Aydın, M. Kahraman, O. Akay, K.S. Diker, Özel mikrobiyoloji kitabı (pp. 110-124). Ankara, Türkiye: Medisan Yayınevi. [The Microbiology Book (pp.110-124). Ankara, Turkey: Medisan Press]. [in Turkish]

7. Doganay M., Aygen B. (2003). Human brucellosis: an overview. Int. J. Infect. Dis. 7, 173-182. https://doi.org/10.1016/S1201-9712(03)90049-X

8. Perez-Sancho M., Garcia-Seco T., Dominguez L., Alvarez J. (2015). Control of animal brucellosis, The most effective tool to prevent human brucellosis. http://www.intechopen.com/:http://www.intechopen. com/books/updates-on brucellosis/control-of-animal-brucellosis-the-most-effective-tool-to-prevent-human-brucellosis [accessed on 09.24.2016].

9. World Health Organisation. (2004). Laboratory safety manual, Third edition. Geneva.

10. OIE. Terrestrial Manual Chapter 2.7.2. (2009). Caprine and ovine brucellosis.

11. OIE. Terrestrial Manual Chapter 2.4.3. (2012). Bovine brucellosis.

12. Godfroid, J., Scholz, H.C., Barbier, T., Nicolas, C., Wattiau, P., et al. (2011). Brucellosis at the animal/ ecosystem/human interface at the beginning of the 21st century. Prev Vet. Med. 102, 118-131. https://doi.org/10.1016/j.prevetmed.2011.04.007 PMid:21571380

13. Krstevski K., Naletoski I., Mitrov D., Mrenoshki S., Cvetkovikj I., Janevski A., Dodovski A., Djadjovski I. (2015). Application of fluorescence based molecular assays for improved detection and typing of Brucella strains in clinical samples. Mac Vet Rev. 38 (2): 223-232. https://doi.org/10.14432/j.macvetrev.2015.09.055

14. Marin, C.M., Alabart, J.L., Blasco, J.M. (1996). Effect of antibioctics contained in two Brucella selective media on growth of Brucella abortus, B. melitensis, and B. ovis. J. Clin. Microbiol. 34 (2): 426-428.

PMid:8789029 PMCid:PMC228811 
15. Stack, J.A., Harrison, M., Perrett, L.L. (2002). Evaluation of a selective medium for Brucella isolation using natamycin. J. Appl. Microbiol. 92, 724-728.

https://doi.org/10.1046/j.1365-2672.2002.01595.x PMid:11966913

16. Hornsby, R.L., Jensen, A.E., Olsen, S.C., Thoen, C.C. (2000). Selective media for isolation of Brucella abortus strain RB51. Vet. Microbiol. 73, 51-60. https://doi.org/10.1016/S0378-1135(00)00149-8

17. Marin, C.M., Jimenez De Bagues, M.P., Barberan, M., Blasco, J.M.(1996). Comparison of two selective media for the isolation of Brucella melitensis from naturally infected sheep and goats. Vet. Res. 138, 409-411.

https://doi.org/10.1136/vr.138.17.409

18. Vicente, A.F., Antunes, J.M., Lara, G.H., Mioni, M.S.R., Allendorf, S.D., et al. (2014). Evaluation of three formulations of culture media for isolation of Brucella spp. regarding their ability to inhibit the growth of contaminating organisms. Biomed. Res. Int. 702072.

PMid:24949466 PMCid:PMC4052881

19. Pappas, G. (2010). The changing Brucella ecology: novel reservoirs, new threats. Int. J. Antimicrob. Ag. $365,8-11$.

https://doi.org/10.1016/j.ijantimicag.2010.06.013 PMid:20696557

20. Farrell, I.D. (1974). The development of a new selective medium for the isolation of Brucella abortus from contaminated sources. Res. Vet. Sci. 16, 280-286.

PMid:4369280

21. De Miguel, M.M., Marin, C.M., Munoz, P.M., Dieste, L., Grillo, M.J., Blasco, J.M. (2011). Development of a selective culture medium for primary isolation of the main Brucella species. J. Clin. Microbiol. 49(4): 1458-1463.

https://doi.org/10.1128/JCM.02301-10

PMid:21270216 PMCid:PMC3122841

22. Jones, L.M., Morgan, W.W. (1958). A preliminary report on a selective medium for the culture of Brucella, including fastidous types. Bull. World. Health. Organ. 19 (1): 200-203.

PMid:13585070 PMCid:PMC2537688

23. Drancourt, M., Raoult, D. (2007). Cost-effectiveness of blood agar for isolation of Mycobacteria. Plos. Negl. Trop. D. 1, 83.

https://doi.org/10.1371/journal.pntd.0000083

PMid:18060087 PMCid:PMC2100370
24. Martin, W.K., Mattick, K.L., Harrison, M., Humphrey, T.J. (2002). Evaluation of selective media for Campylobacter isolation when cycloheximide is replaced with amphotericin B. Lett. Appl. Microbiol. 34, 124-129.

https://doi.org/10.1046/j.1472-765x.2002.01058.x PMid:11849508

25. Alton, G.G., Jones, L.M., Angus, R.D., Verger, J.M. (1988). Techniques for the brucellosis laboratory. Paris, France: Institut National de la Recherche Agromique-INRA.

26. International Organisation for Standartization. ISO/TS Technical Spefication 11133-1. (2009). Microbiology of food and animal feeding guidelines on preparation and production of culture media. Geneva, Switzerland: ISO.

27. Her, M., Choa, D.H., Kang, S.I. (2010). The development of a selective medium for the Brucella abortus strains and its comparison with the currently recommended and used medium. Diagn. Microbiol. Infect. Dis. 67, 15-21.

https://doi.org/10.1016/j.diagmicrobio.2009.12.013 PMid:20385349

28. Jones, L.M., Dubray, G., Marly, J. (1975). Comparison of methods of diagnosis of Brucella ovis infection of rams. INRA editions. 6 (1): 11-22.

29. O’ Grady, D., Byrne, W., Kelleher, P., O'callahan, H., Kenny, K., Heneghan, T., Power, S., Egan, J, Ryan, F. (2014). A comparative assessment of culture and serology in the diagnosis. Vet. J. 199, 370-375. https://doi.org/10.1016/j.tvj1.2014.01.008 PMid:24507882

30. Ferreira, A.C., Almendra, C., Cardoso, R., Pereira, M.S., Pereira, A.B., Luikart, G., Correa De Sa, M.I. (2012). Development and evaluation of a selective medium for Brucella suis. Res. Vet. Sci. 93, 565-567. https://doi.org/10.1016/j.rvsc.2011.09.004 PMid:21968103

31. Nardi Junior, G., Megid, J., Vicente, A.F. (2015). Comparison of Brucella agar, CITA and Farrell media for selective isolation of Brucella abortus from semen of bovine bulls. Afr. J. Microbiol. Res. 9 (9): 617-620. https://doi.org/10.5897/AJMR2014.7252

32. Fatolahzadeh, B., Maleknejad, P., Hejazi, M.J., Pyri, H. (2009). Development and evaluation of TUMS medium, a novel biphasic culture medium for isolation of Brucella spp. from patients. Iran. J. Microbiol.1 (2): 21-25. 
33. Keppie, J., Williams, A., Witt, K., Smith, H. (1965). The role of erythritol in tissue localization of the Brucellae. Brit. J. Exp. Pathol. 46, 104-108.

PMid:14295553 PMCid:PMC2093692

34. Garcia-Lobo, J.M., Sangari Garcia, J.F. (2005). Erythritol metobolism and virulence in Brucella. In: I. Lopez-Goni, I. Moriyon (Eds.), Brucella, Molecular and Celular Biology, (pp.223-236). Spain: Taylor \& Francis.

35. Seleem, M.N., Boyle, S.M., Sriranganathan N. (2008). Brucella: A pathogen without classic virulence genes. Vet. Microbiol. 129, 1-14. https://doi.org/10.1016/j.vetmic.2007.11.023 PMid:18226477
36. Poester, F.P., Samartino, L.E., Santos, R.L. (2013). Pathogenesis and pathology of Brucellosis in livestock. Revue scientifique et technique (International Office of Epizootics). 32 (1): 105-115. https://doi.org/10.20506/rst.32.1.2193 PMid:23837369

37. Sperry, J.F., Robertson, D.C. (1975). Inhibition of Growth by Erythritol Catabolism in Brucella abortus. J. Bacteriol. 124 (1): 391-397.

PMid:170249 PMCid:PMC235907 